\title{
Urological Surgeries During Exit from National Lockdown During COVID-19 Pandemic
}

\author{
Devanshu Bansal $^{1} \cdot$ Samit Chaturvedi ${ }^{1} \cdot$ Anant Kumar $^{1}$ \\ Received: 29 June 2020 / Accepted: 15 August 2020 / Published online: 7 September 2020 \\ (C) Association of Surgeons of India 2020
}

\section{Dear Editor In Chief}

The first case of coronavirus disease (COVID-19) in India was reported on 30 January 2020 and the government declared a nationwide lockdown on 25 March 2020 [1]. However, a lockdown is not a cure and surgical management of non-COVID urologic illnesses cannot be indefinitely postponed [2]. Recommendations to restart surgical care are essential as the lockdown is eased.

Partial utilization of resources should initially be done to spare for a sudden increase in demand due to surge in cases. Surgeries that have been postponed once during lockdown (for 3 or 6 months) should not be re-postponed. Guidelines have previously proposed postponement of uro-oncologic surgeries by 3-6 months for small renal masses, low-risk nonmuscle invasive bladder cancer, low-risk upper tract urothelial cancers, low-high-risk localized prostate cancer, and early penile cancer [3, 4]. Analysis of our case load (unpublished) of oncologic surgeries and renal transplants performed during lockdown compared with a similar duration in 2019 showed a decline of $87.7 \%$ and $70.7 \%$ respectively (Fig. 1). Cancer care for patients previously postponed should reinitiate. Key safety concerns include older age, increased comorbidities, complex nature of surgeries, and more complicated hospital stay [5]. Oncological patients should be encouraged to come forward for care and their scheduling done as per severity and urgency of their disease. Semi-

Anant Kumar

dranantkumar57@gmail.com

Devanshu Bansal

db.golem@gmail.com

Samit Chaturvedi

samit.uro@gmail.com

1 Department of Urology, Renal Transplant, Robotics and Uro-oncology, Max Superspecialty Hospital, Saket, New Delhi 110017, India urgent live renal transplants like lack of secure vascular access and for those not doing well on dialysis should be allowed [6]. All precautions should be taken to reduce exposure of healthy donor in hospital during investigations [7]. Prolonged prohibition on renal transplantation is likely to have a significant adverse effect on quality of life and survival of recipients. Benign urologic conditions can be divided into three categories (Table 1), and may have significant detrimental effect on quality of life of patients. Unfortunately, this aspect of treatment has not been adequately addressed in studies.

While scheduling surgeries, a tiered system as proposed by us may be followed, so that patients who have been postponed once are able to get the required care (Table 1). Once planned for surgery, every patient should be screened for symptoms and tested for COVID-19. COVID-19-positive patients should be managed in a different dedicated ward and operation theatre or sent to a designated COVID-19 hospital. It should be realized that these tests have a high false negative rate (median $38 \%$ on the day of symptom onset), so a negative test should not relax use of adequate safety precautions by the doctors [8]. Duration of preoperative admission should be reduced to limit patient exposure. Informed written consent should be taken about potential risk of acquiring COVID-19 in the postoperative period before going ahead with surgery. During surgery, all internationally recommended precautions should be followed. Postoperative hospital stay should be minimized and follow-up may be done virtually. Proper medical record keeping should be ensured to avoid litigation. Absorbable skin sutures may be used wherever feasible. Drain or Foley's catheter may be removed at nearby clinic or home nursing facility to limit hospital visits.

In conclusion, routine urological surgical care may be restarted using a tiered surgical reopening plan and adequate precautions. 
160

140

120

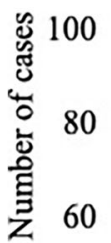

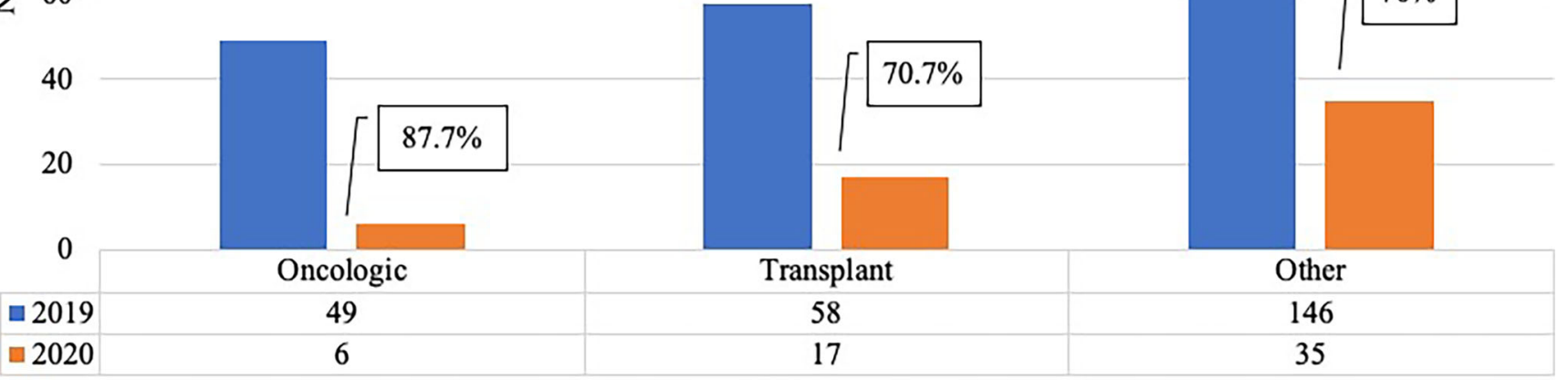

Distribution of cases

Fig. 1 Case load performed during 6 weeks of lockdown (phases 1 and 2) at our institute in 2020 compared with that in a similar time period during the previous year (2019)

Table 1 Classification of benign urological conditions and proposed tiered system for scheduling urological surgeries in COVID-19 times

Classification of benign urological conditions in COVID-19 times

Category

Emergent care required

(may be immediately life threatening)

Immediate care not required

May later have detrimental effect on quality of life

May require more complex treatment later if not done presently

Elective indication for treatment

Proposed tiered system for scheduling urological surgeries Priority

Emergent/high/complex cases (first case on the list) Postponed oncology cases

Postponed benign cases

Postponed elective cases (only if resources and low regional COVID-19 case load permits)
Examples

Obstructed ureteric stone with solitary kidney or urosepsis

Urinary tract obstruction with obstructive uropathy

Acute ischemia such as strangulated inguinal hernia/testicular torsion/para-phimosis

Trauma with hemodynamic instability

Blocked catheter

Infections such as infected prostheses/Fournier gangrene Staghorn stone with chronic renal dysfunction/infection

Chronic ureteric stents

Undescended testes

Proximal hypospadias

Ureteropelvic junction obstruction with possible renal deterioration

Bladder outlet obstruction with retention managed temporarily with catheterization

Male infertility with advanced age of female partner Asymptomatic renal stones

Hydrocele

Isolated distal hypospadias

Ureteropelvic junction obstruction with stable renal function

Male infertility with young age of female partner

Type of surgeries (examples)

Non-deferrable cancers, renal transplants

TURBT, radical prostatectomy for carcinoma prostate, partial nephrectomy

Orchidopexy, TURP, PCNL/URSL/RIRS, pyeloplasty, urethroplasty for patients on catheter

Circumcision, hydrocele repair, surgery for small stones, functional urology cases 


\section{Compliance with Ethical Standards}

Conflict of Interest The authors declare that they do not have any conflict of interest.

\section{References}

1. Nair A, Gandhi R, Natarajan S (2020) Effect of COVID-19 related lockdown on ophthalmic practice and patient care in India: results of a survey. Indian J Ophthalmol 68(5):725-730

2. Zhigljavsky A, Whitaker R, Fesenko I, Kremnizer K, Noonan J (2020) Comparison of different exit scenarios from the lock-down for COVID-19 epidemic in the UK and assessing uncertainty of the predictions. ArXiv200404583 Q-Bio [Internet]. https://doi.org/10. $1101 / 2020.04 .09 .20059451$

3. (2020) Coronavirus disease USI information center. usi.org.in.

4. EAU Guidelines Office Rapid Reaction Group: An organisationwide collaborative effort to adapt the EAU guidelines recommendations to the COVID era. https://uroweb.org/guideline/covid-19recommendations $/$ ?type $=$ archive
5. Mehta V, Goel S, Kabarriti R, Cole D, Goldfinger M, AcunaVillaorduna A et al (2020) Case fatality rate of cancer patients with COVID-19 in a New York hospital system. Cancer Discov 10(7): 935-941. https://doi.org/10.1158/2159-8290.CD-20-0516

6. Ritschl PV, Nevermann N, Wiering L, Wu HH, Moroder P, Brandl A et al (2020) Solid organ transplantation programs facing lack of empiric evidence in the COVID-19 pandemic: A By-proxy Society Recommendation Consensus approach. American journal of transplantation : official journal of the American Society of Transplantation and the American Society of Transplant Surgeons 20(7):1826-1836. https://doi.org/10.1111/ajt.15933

7. Bellini MI, Tortorici F, Capogni M (2020) Kidney transplantation and the lockdown effect [published online ahead of print, 2020 May 9]. Transpl Int https://doi.org/10.1111/tri.13639

8. Kucirka LM, Lauer SA, Laeyendecker O, Boon D, Lessler J (2020) Variation in false-negative rate of reverse transcriptase polymerase chain reaction-based SARS-CoV-2 tests by time since exposure. Ann Intern Med 173(4):262-67. https://doi.org/10.7326/M20-1495

Publisher's Note Springer Nature remains neutral with regard to jurisdictional claims in published maps and institutional affiliations. 